Turning problems and freezing of gait in Parkinson's disease: a systematic review and meta-analysis

Peer-reviewed author version

SPILDOOREN, Joke; Vinken, Catherine; Van Baekel, Laura \& Nieuwboer, Alice (2019) Turning problems and freezing of gait in Parkinson's disease: a systematic review and meta-analysis. In: DISABILITY AND REHABILITATION, 41(25), p. 2994-3004.

DOI: $10.1080 / 09638288.2018 .1483429$

Handle: http://hdl.handle.net/1942/28316 


\section{Turning problems and freezing of gait in Parkinson's Disease: A systematic review and meta-analysis.}

Running Head: Turning and freezing of gait

Article category: Systematic review and meta-analysis

Joke Spildooren $^{1 *}$, Cathérine Vinken ${ }^{1}$, Laura Van Vaekel $^{1}$ and Alice Nieuwboer ${ }^{2}$

${ }^{1}$ REVAL - Rehabilitation Research Center-BIOMED, Biomedical Research Institute,

Faculty of Medicine and Life Sciences, Hasselt University, Hasselt, Belgium;

${ }^{2}$ Department of Rehabilitation Sciences, Faculty of Kinesiology and Rehabilitation, $K U$

Leuven, Leuven, Belgium

*corresponding author

Joke Spildooren, $\mathrm{PhD}, \mathrm{PT}$

Agoralaan building A

3590 Diepenbeek

Phone: +32 11269256

E-mail: joke.spildooren@uhasselt.be

Word count: 5268 


\section{Abstract}

Objective: To understand the differences of step and turn parameters between freezers and non-freezers during turning and determine the influence of turn angle and turn characteristics on freezing of gait.

Data Sources: Pubmed and Web of Science were searched from the earliest data available to August 2017.

Study Selection: Case-control studies that examined the differences in turning while walking between freezers and non-freezers were included. Two reviewers selected studies independently.

Data Extraction: Methodological quality was evaluated by two independent reviewers using the STROBE checklist for case-control studies. Mean differences and $95 \%$ confidence intervals were calculated from pooled data for turn duration, peak turn velocity, number of steps and cadence. Center of mass deviation, segmental rotation, phase coordination and freezing of gait frequency were also extracted. When possible, different turning angles or spatial confounds were compared.

Data Synthesis: Sixteen studies met the inclusion criteria. Freezing of gait occurred in $38.2 \%$ of the freezers. Freezing appeared most frequently at the end of a turn and at the inner leg of the turn cycle. The meta-analysis revealed that turning in freezers was characterized by an increased turn duration, cadence and number of steps and a decreased peak turn velocity. Qualitative analysis showed that results concerning step width, step length and step time variability were inconsistent. Turning was characterized by an increased head-pelvis coupling and worse coordination in freezers compared to non-freezers. A decreased medial deviation of the Center of mass was present prior to a freezing-episode.

Conclusions: Both step and rotational parameters differed in freezers compared to non-freezers while turning. These differences increased with increasing task complexity (i.e. larger turning angle or spatial confounds during turning). The results suggest that improving axial rotation could be a valuable rehabilitation target to ameliorate freezing.

Keywords: turning, Parkinson's Disease, freezing of gait, axial rotation, step parameters 


\section{Introduction}

Freezing of gait is one of the most disabling motor symptoms [1] in Parkinson's Disease (PD) affecting 47 to 80 percent of the patients [2] and is further referred in this review as freezing. Freezing is defined as "a brief, episodic absence or marked reduction of forward progression of the feet despite the intention to walk" $[3,4]$ and is highly related to falls [5], patients' quality of life [6] and levels of activity [7]. Freezing is heterogeneous and manifests as (1) showing trembling movements of the legs; or (2) shuffling with small steps of forward progression; and (3) no movements of the trunk and limbs [8]. This akinetic form is less common [3,9]. The circumstances in which freezing can be provoked are diverse. The most common are: turning, gait initiation, walking in tight quarters and dual tasking. In addition, triggering of freezing is influenced by the environment, cognitive function and stress $[8,10]$.

Thirty-five to $45 \%$ of all steps during daily life activities are made during turning [11]. Turning is an asymmetrical motor task [12] characterized by a decreased step length [13] and increased stance phase [14] at the inner leg in combination with an increased swing velocity at the outer leg of the turn. Gaze rotation occurs approximately $200 \mathrm{~ms}$ before the start of the turn. This so called "go where you look-strategy" [15] occurs also in the dark [16]. After the head, also the trunk, pelvis and feet rotate to the inner side of the turning cycle and the Center of Mass (COM) deviates to the same side $[13,17]$. During turning, velocity decreases $[13,17]$ and stride width increases to improve stability of body weight during trunk rotation and lateral translation [18].

Turning problems are an early sign of the progression of PD [19], as recently summarized in a narrative review by Hulbert et al [20]. Compared to age-matched controls, people with PD need more time and steps to complete a turn. Turning is characterized by a broader turning-arc [21] and step length is even more reduced during tighter turns [20]. People with PD are less likely to take cross-over steps especially with 
increasing turning-angles [22]. Besides spatio-temporal impairments, the initiation of head orientation is postponed in PD [23], resulting in a more coupled start of head and trunk rotation in comparison to the top-down coordination in healthy controls $[20,24]$. Further, turning is characterized by an increased forward inclination and instability of the COM trajectory in people with PD [20].

Ninety-four percent of freezers (i.e. patients with PD and freezing) report difficulties in turning [25]. Despite the fact that turning problems are an important trigger of freezing-episodes [26] and that the severity of freezing during turning is correlated to decreased activities of daily living in PD [7], not much is known about the turning difficulties related to freezing. Most studies on turning quality differentiate only between healthy controls and Parkinson's Disease patients without a further distinction between freezers and non-freezers. Earlier work showed that freezers turn more slowly [27], with a higher cadence [28] and tend to increase turning-arc [21] in comparison to non-freezers (i.e. PD patients without freezing). Clean comparisons between freezers and non-freezers are often hampered by disease confounders, such as differences in disease severity, medication intake and cognitive capacity. Therefore, the current systematic review was aimed at investigating whether this pattern of results was confirmed by more recent work and when comparing different cohorts. In addition, both the influence of turning-angle and turning arc (i.e. spatial confounds) was investigated. We prioritized the study of spatio-temporal as well as axial mobility parameters as possible contributing factors to freezing-related turning problems. To date no such literature review has been undertaken.

Therefore, the following research questions will be investigated:

(1) What are the differences in spatio-temporal parameters between freezers and non-freezers during turning found in the studies published to date? 
(2) What are the differences in axial rotation parameters between freezers and nonfreezers during turning?

\section{Methods}

\section{Search strategy}

This review was completed in accordance with the Preferred Reporting Items for Systematic Reviews and Meta-analysis (PRISMA) protocol [29]. The electronic databases Pubmed and Web of Science were searched from December 2016 to August 2017 with language restriction English or Dutch. A PICO was established which consisted of: (P) PD patients with freezing; (I) Turning while walking; (C) PD patients without freezing; $(\mathrm{O})$ rotation- and step parameters. "Parkinson's Disease", “Parkinson”, “turning”, “turn”, “pivot”, “circumduction”, “freezing of gait” and "freezing" were used as search terms. A more detailed description of the search strategy can be found in supplementary table 1 . The reference lists of relevant articles were checked to identify other potentially eligible studies.

\section{Study Selection}

Studies were considered for inclusion, when they pertained to participants with idiopathic PD only and those which compared groups of freezers and non-freezers. Furthermore, studies comparing axial rotation or spatiotemporal parameters while turning were included. Axial rotation was defined as rotation of head, trunk, pelvis and feet in relation to each other or in relation to the COM. Studies concerning treatment methods for freezing were included when baseline results without treatment were presented in the manuscript. Review or meta-analysis and abstracts from conference 
proceedings were excluded. Furthermore, studies in other languages than Dutch or English were excluded.

\section{Data Collection}

Two researchers (LV and CV) screened the search results independently according to the title and abstract. When the abstract was potentially eligible by one of the researchers, the full text was obtained for complete assessment and duplicates were removed. The two researchers independently evaluated the full text for inclusion. Disagreement between the researchers LV and CV was resolved by consultation of the other reviewers JS and AN. Article inclusion was determined by a final screening of the full text by JS.

LV and CV independently extracted the data from the included studies. Information regarding study population, study design, test protocol (type of turning), outcome measures and results were extracted from the full text of the included studies. The following outcome measures were reported: freezing-frequency, step parameters during turning (i.e. turn duration, peak turn velocity, steps to turn, cadence, step length and step width, gait variability, turn depth and turn width, turn type), axial rotation parameters (head-pelvis dissociation and COM behaviour). When additional information was needed, the authors were contacted by e-mail. Disagreement between the researchers (LV and CV) was resolved by consultation of the third reviewer JS.

\section{Quality Assessment}

All included articles were categorized as case-control studies (i.e, freezers (FRs) were determined as case and non-freezers (nFRs) as controls). To assess the quality of these articles, the STROBE checklist for case-control studies was used [30]. For every article 
the STROBE checklist evaluated 32 items, categorised in six sections: title and abstract, introduction, methods, results, discussion and other information. Each item was scored nominally (yes $=1$ or no $=0$ ) to assess the quality. Depending on the total score, the evaluated article was classified as having a low (0-40\%), moderate (41-60\%), high (61$80 \%)$ or very high (81-100\%) quality. Quality assessment was performed by two independent raters (LV and CV) who initially performed the evaluation individually. Disparities were resolved by discussion or consultation with a third reviewer (JS). Articles were not excluded based on methodological quality. In addition, we added a methodological analysis of the turning methodologies used and checked whether the freezer and non-freezer groups were comparable.

\section{Statistical Analysis}

Meta-analyses were conducted using Review Manager Version 5.3. Means and standard deviations from individual studies were used to calculate mean differences and $95 \%$ Confidence Intervals (CI) between freezers and non-freezers. Studies were grouped according to turning angle in the following 4 subgroups: $90^{\circ}, 120^{\circ}, 180^{\circ}$ and $360^{\circ}$. When studies reported multiple data within the same turning angle (i.e. turning to the disease dominant and non-dominant side separately or turning with different turn widths), means and standard deviations were pooled to give a single result for inclusion in the meta-analysis. Heterogeneity was quantitatively analysed with the $\mathrm{I}^{2}$ test. The level of significance was set at $\mathrm{p}<0.05$ for all statistical analyses. If conducting a metaanalysis was not possible due to the low number of studies available for a specific parameter $(\mathrm{n}<3)$, a descriptive synthesis of the results was performed.

\section{Results}




\section{Literature Search}

The first search in December 2016 resulted in 140 articles (i.e. 47 articles on Pubmed and 93 on Web Of Science). After excluding duplicates, 99 articles remained for further analysis.

Exclusion was based on different criteria: review $(n=15)$, written in other languages than Dutch or English $(n=3)$, no full text available $(n=5)$, no evaluation of turning or gait parameters $(\mathrm{n}=33)$ and no comparison between freezers and non-freezers $(n=30)$.

The second search in August 2017 revealed 5 extra articles in Pubmed and 9 in Web of Science. Finally, 16 articles met the inclusion criteria. A detailed flowchart of the literature search is presented in figure 1.

[Figure 1 near here]

\section{Characteristics of Included Studies}

The 16 studies included in this review consisted of 589 PD patients of which 270 experienced freezing of gait (501 PD patients included for the meta-analysis of which 229 experienced freezing of gait) across six countries (Belgium [21,27,28,31-34], Canada [35], France [36], Germany [37], Spain [38], USA [39-43]).

Data-extraction of the 16 included articles is presented in supplementary table 2 (short version in table 1). An analysis of the participants was made, in which all the characteristics of the freezers and non-freezers were listed. A brief reporting of the protocol and the results were presented. Finally, the strengths and limitations of the included articles were presented in supplementary table 3. 
Quality Assessment of Included Studies

The STROBE checklist (Supplementary table 4) for case-control studies was used to assess the quality of the included articles. All articles were classified as high quality except for the study of Sijobert et al. [36] which was classified as a moderate quality article. No articles were classified to the category low or very high quality (Supplementary table 5). Overall, study designs controlled adequately for selection bias except for Sijobert [36] and Fietzek [37] (table 1).

[Table 1 near here]

\section{Subject Characteristics}

14 out of 16 articles used the (New) Freezing of Gait Questionnaire [44,45] to classify the patients in freezers and non-freezers. The other two articles categorized the PD patients based on observation of freezing-episodes during the experimental protocol $[35,36]($ table 1$)$.

Ten articles examined the participants during the OFF-state of medication [28,31-34,38-42] and four articles during the ON-state [21,27,35,37]. The study of McNeely et al. [43] was performed during both $\mathrm{ON}$ - and OFF-state to investigate the effect of medication on turning and gait parameters in PD patients with and without freezing of gait. To prevent an over-representation of the results of McNeely et al., only the data-extraction while OFF-medication was presented in the meta-analysis. Only one article did not report the medication state in which the PD patients were examined [36]. (table 1)

\section{Turning Characteristics}


In general, the main goal of all the included articles was the comparison of turn performance in freezers and non-freezers. Nine studies investigated the effect of an intervention (i.e. medication [43], cueing strategies [21,27,32,38] and electrical stimulation [36]) or dual-task [28,34,41] on the turn performance. Only the dataextraction of the baseline turning characteristics without treatment or dual-task were included in the review. In two articles, a dual task was added in the middle of the turn (i.e. walk to the wall, touch the button and turn around without stopping [38] or walk to a chair, pick up a tray with two cups of water and turn around [27]). These turns were included in the analysis.

In the different studies, a distinction was made between three turn modalities (table 1). Participants either had to turn on the spot $[37,39,40,43]$, turn while walking with a small standardised turning arc (narrow turn with spatial constraint) $[28,31-35,42]$ or turn with an unspecified turning-arc [21,27,36,38,41]. In addition, a wide range of different turning angles from $90^{\circ}$ tot $360^{\circ}$ to the left and right side were studied. To address this heterogeneity, we grouped our studies based on the turning angles.

\section{Evaluation Methods}

Nine studies used the infrared 3D camera system of Vicon Motion Analysis (VICON, Oxford Metrics, Oxford, UK) [21,28,31-34], Motion Analysis Corporation (Motion Analysis Corporation, Santa Rosa, CA) [40,43] or Optotrak system (Waterloo, Canada)[35] with retroreflective markers to analyse the turn performance. The seven remaining articles used other measuring methods (i.e. foot switches on the sole of each foot $[38,42]$, inertial sensors $[37,39,41]$, video recordings [36], accelerometers [27]) to analyse the gait parameters objectively (supplementary table 2). 


\section{Freezing of Gait Frequency}

Ten articles reported the presence of freezing in relation to turning [21,27,28,31-

$33,35,38,39,42]$. In total, freezing of gait occurred in 58 of 152 freezers (i.e. $38.2 \%$ ).

More specifically, freezing of gait was reported in between 38,5 [33]-100\% [38] of freezers tested in the OFF-phase and in between 11,1 [21] - 40\% [35] of the freezers when tested in the ON-phase. McNeely et al. [43] reported freezing as "rare" during the testing without further information.

Two articles demonstrated an increased frequency of freezing-episodes in turns with large turn angles. In Bhatt et al. [35], freezing-episodes occurred more frequently during $120^{\circ}$ and $180^{\circ}$ turns compared to $90^{\circ}$ turns. Spildooren et al. [28] confirmed these results when comparing $180^{\circ}$ and $360^{\circ}$ turns during dual task conditions. However, the increase in FOG-frequency when turning $360^{\circ}$ in comparison to $180^{\circ}$ was not demonstrated during single task conditions. In addition to the influence of turning arc on the occurrence of freezing, a correlation between the radius of the turning cycle and freezing was demonstrated by Peterson et al. [42] implicating that freezingfrequency increased when walking a narrow turn with spatial constraint.

A higher freezing-frequency at the end of the turn was demonstrated by Bengevoord et al. [31], as freezing occurred most frequently during the fourth turning quadrant of a $180^{\circ}$ turn. In addition, freezing-episodes at the end of the turn were characterized by a shorter duration in comparison to the beginning of the turn $(0.63 \mathrm{vs}$ 3.71s; $\mathrm{p}=0.003$ ) [33]. Even though a significantly larger freezing-frequency was found at the inner leg of the turn cycle ( $\mathrm{p}=0.03)$, no influence of disease dominance nor turn direction was found on freezing-frequency in a study with 94 freezing episodes resulting in a p-value of 0.31 and 0.75 respectively [32]. 
Trials with freezing were excluded for further gait- and turn analysis in most of the studies. However, five studies [35,37-39,42] included the freezing-episodes and three studies $[36,40,41]$ gave no further information on the in- or exclusion of freezingtrials.

\section{Comparison of Step Parameters between Freezers and Non-Freezers}

\section{Turn Duration and Peak Velocity}

Turn duration was analysed in the majority of studies $(n=12)$. Figure 2 reveals a significantly longer turn duration in freezers (FRs) in comparison to non-freezers (NFRs) of 1.24s (95\% CI, 0.76-1.72; $\mathrm{n}=510)$. The sub-analysis showed that the difference of turn duration is related to the turning angle (i.e. difference of $3.76 \mathrm{~s}$ during $360^{\circ}$ turns in comparison to $0.92 \mathrm{~s}$ during $180^{\circ}$ turns and no significant difference during $90^{\circ}$ turns). The data of $90^{\circ}$ turns were based on only one study of 8 freezers and 14 nonfreezers and can therefore not be conclusive [40]. However, these freezers did have an increased turn duration in comparison to non-freezers when the turning angle increased from 90 to $180^{\circ}$ (figure 2 ).

[Figure 2 near here]

Additionally, Bengevoord et al. [31] divided turn duration in four turning quadrants of a $180^{\circ}$ turn. Only in the first quadrant $\left(10^{\circ}-50^{\circ}\right)$, freezers presented a longer turn duration compared to non-freezers. However, freezing events occurred more frequently in the fourth quadrant.

In figure 3 , the meta-analysis of the peak turn velocity is visualised. Peak turn velocity was significantly lower in FRs in comparison to $\mathrm{nFRs}(\mathrm{p}=0.004)$ with a mean difference of $20.55 \%$ s (95\% CI, 6.66-34.45; $\mathrm{n}=84)$ [39,41]. 
[Figure 3 near here]

\section{Turn Steps}

Seven studies assessed the number of steps to turn as an outcome $[21,28,32,35,37,40,43]$. Figure 4 illustrates that freezers needed significantly more steps to complete a turn in comparison to non-freezers (95\% CI, 2.20-5.24; $\mathrm{n}=274)$ with a mean difference of 3.72 steps. The sub-analysis showed that the difference between the number of steps, performed by freezers and non-freezers, during a $90^{\circ}$ and $180^{\circ}$ turns were comparable, i.e. 3.3 steps (i.e. $106,5 \%$ increase, $p=0.01$ ) and 3.19 steps (i.e. $50,5 \%$ increase, $p<0.001)$ respectively. The difference in number of steps between freezers and non-freezers increased to a mean difference of 4.98 steps (i.e. $39,2 \%$ increase) during $360^{\circ}$ turning $(95 \% \mathrm{CI}, 3.04-6.91 ; \mathrm{n}=134)$.

The $\mathrm{I}^{2}$ of $83 \%$ implied a high heterogeneity in the sub-analysis of the number of steps for $180^{\circ}$ turning.

\section{[Figure 4 near here]}

\section{Cadence}

Four articles assessed cadence (steps/min) as an outcome $[28,32,34,35]$. The metaanalysis revealed a significantly higher cadence in freezers in comparison to nonfreezers of 10.1 steps/minute $(95 \% \mathrm{CI}, 4.87-15.33 ; \mathrm{n}=208)$. The sub-analysis showed that the increased cadence is related to the turning angle and was only significant with a mean difference of 12.26 steps/minute while turning $180^{\circ}$ (95\% CI, 4.62-19.9; $\mathrm{n}=75$ ) (figure 5).

The lack of significant differences during $90^{\circ}$ and $120^{\circ}$ turning might be explained by the fact that these turning angles were only registered in the study of Bhatt et al. [35] The analysis of the cadence during $360^{\circ}$ did not demonstrate significant differences 
between freezers and non-freezers $(95 \% \mathrm{CI}, 7.74[-1.02,16.51], \mathrm{P}=0.08)$ as the study of Vervoort et al. [34] and Spildooren et al. [28] had contradictory results.

[Figure 5 near here]

When the influence of turning angle on cadence was analyzed separately, the study of Bhatt et al. [35] demonstrated a stepwise augmented cadence when turning angle increased from $90^{\circ}$ to $120^{\circ}$ and to $180^{\circ}$ in freezers. This reaction was not seen in the non-freezer group when turn angle increased from $90^{\circ}$ to $120^{\circ}$. In the study of Spildooren et al. [28] increments of cadence in freezers was only significant when the increasing turn angle was combined with dual tasking.

\section{Step Length, Step Width and Gait Variability}

Analysis of the differences in step length between freezers and non-freezers during turning was performed in two articles [21,35], hence a meta-analysis was not performed. In both studies, step length was calculated according to the proposed analysis by Huxham et al. [18] for non-linear walking. Both studies did not find a difference in step length during turning between freezers and non-freezers. The step length was smaller at the inner side of the turning cycle [21]. In addition, step length decreased in both groups when turning angle increased (i.e. $90^{\circ}, 120^{\circ}$ and $180^{\circ}$ ) [35].

Step width during turning was analyzed in only three articles. Therefore, influence of turning angle was not examined in a meta-analysis. Step width was calculated according to the proposed analysis by Huxham et al. [18] for non-linear walking. During $180^{\circ}$ turning, non-freezers had a significantly larger step width in comparison to freezers of $2.49 \mathrm{~cm}(95 \% \mathrm{CI}, 0.49-4.49 ; \mathrm{n}=69)$ (figure 6). 
[Figure 6 near here]

Willems et al. found no significant differences in step width between freezers and non-freezers when testing in the ON-phase of the medication cycle [21]. Bengevoord et al. [31], however, demonstrated a significant smaller step width in freezers especially at the end of the turn (i.e. during the fourth turning quadrant (130$\left.170^{\circ}\right)$ ). In a supplementary analysis of trials with and without freezing, a smaller step width was characteristic for the pre-freezing phase compared to turning trials without freezing. Bhatt et al. [35] confirmed these results as non-freezers increased their step width in reaction to an increasing turning angle in comparison to freezers who demonstrated no changes in step width.

Three studies examined gait variability while turning. Step time variability was not significantly different between freezers and non-freezers $[21,35]$. However, only step time variability in freezers increased significantly when turning angle increased (i.e. $90^{\circ}$ turning in comparison to $120^{\circ}$ and $180^{\circ}$ turning) [35].

Peterson et al. [42] measured the coordination during turning expressed as the phase coordination index (PCI) [46]. Freezers had a larger PCI relative to non-freezers which signified a worse coordination during turning. This high PCI was especially visible during a narrow turn and correlated with a high severity of freezing in freezers.

Turn Depth, Width and Turn Type

Non-freezers preferred cross-over turning strategies in contrast to freezers during $90^{\circ}$ turns [35]. This difference was no longer significant when the turning angle increased. 
When no instructions were given on turning strategy, turn depth and arc were significantly larger in freezers in comparison to non-freezers while turn width was comparable in both groups [21]. When turning-arc was reduced by spatial constraints, turn duration and amount of steps to turn increased in freezers [37]. In contrast, no difference in turn duration was found in non-freezers and the amount of steps increased only when the turning arc was reduced to a square size of 30 centimeters.

\section{Comparison of Axial Rotation between Freezers and Non-Freezers}

\section{Head-Pelvis Dissociation}

Two articles analyzed the onset time of the head, trunk and pelvis rotation in freezers compared to non-freezers $[33,43]$. During turn preparation a craniocaudal sequence (i.e. earlier head rotation relative to pelvis and trunk rotation) was apparent in both groups. This craniocaudal sequence was related to turn velocity as freezers turned slower in the trials without activation of the sternocleidomastoid muscle in comparison to trials with a clear sternocleidomastoid onset, suggesting a relationship between the activation of the sternocleidomastoid muscle and turning difficulties [43].

A larger delay of head rotation was demonstrated in the freezer group in the study of Spildooren et al. and in the non-freezers group in the study of McNeely et al. The rotation onset of pelvis and trunk relative to turn onset did not differ between the two groups.

When freezers were analyzed in detail, the craniocaudal sequence disappeared in turn trials with freezing-episodes according to Spildooren et al. [33].

During the turn, the maximum head-pelvis separation was delayed in freezers in comparison to non-freezers, irrespective of the occurrence of freezing-episodes during the trial. The timing of maximum head-pelvis separation was correlated to neck rigidity [33]. 
The head-pelvis separation (i.e. magnitude of axial rotation) was only discussed in the study of Spildooren et al. [33] and was different in freezers in comparison to aged-matched controls in the beginning of the turn. However, this was not related to neck rigidity[33].

\section{COM Behavior}

The COM behavior was analyzed between freezers and non-freezers during four turning quadrants and during pre-freezing conditions by Bengevoord et al. [31]. The analysis of the turning quadrants revealed no significant differences in COM velocity, medial or anterior position between freezers and non-freezers. When pre-freezing conditions of freezers were analyzed, a more anterior and less medial positioned COM was demonstrated compared to trials without freezing-episodes.

\section{Discussion}

This systematic review is the first to evaluate the differences in stepping and axial behaviour between freezers and non-freezers while turning, one of the most triggering factors of freezing. In total, 16 articles of moderate to high quality were included. Only two studies classified freezers and non-freezers based on an observation of freezingepisodes during an experimental protocol. This is a more objective approach relative to the New Freezing of Gait Questionnaire (used in the other studies). However, freezing is an intermittent phenomenon which is difficult to provoke in a laboratory setting [47]. The most prevalent outcome parameters in the studies were freezing frequency $(n=10)$ and gait parameters such as turn duration $(n=12)$, total steps $(n=7)$ and cadence $(n=4)$.

Freezing frequency varied between studies, pending on the inclusion criteria, the medication state during data collection (ON or OFF-phase of the medication cycle), 
turning-angle and turning-arc. Freezing frequency tended to increase with increasing turning-angles [35], especially during dual-tasking [28], and increased during narrow turns [42] and is consequently related to increased task complexity. A higher freezing frequency was demonstrated at the end of the turn [31]. This end of the turn was characterized by a decreased step width and anterior and lateral COM deviation in freezers which might suggest a relation between balance and freezing.

Overall, we found that across studies, freezers turned with a larger turn duration, slower peak turn velocity, more steps and larger cadence compared to non-freezers. Turning angle proved an important trigger for this pattern, as sub-analysis revealed more group differences during a $180^{\circ}$ and $360^{\circ}$ turn. One exception was that, Vervoort et al. [34] demonstrated a larger cadence in non-freezers compared to freezers during $360^{\circ}$ turns in contrast to Spildooren et al. [28]. This could be explained by the turning instructions as Vervoort expected the turn to be performed as fast as possible whereas in the study of Spildooren et al. [28] turning at a comfortable speed was required. As a result, freezers had comparable cadence in both studies (i.e. 119,18 versus 119,93 steps/min) but non-freezers had a significant higher cadence in the study of Vervoort et al. [34] (i.e. 129,53 versus 106,27 steps/min) implying the capacity to adapt turning velocity in the non-freezers. These results have to be interpreted against significant heterogeneity, which was present in the sub-analysis of the number of steps for $180^{\circ}$ turning. Inclusion of the study of Willems et al. [21], which was performed during the ON-phase of the medication cycle, may have been the cause of this heterogeneity. Overall, group differences on turn duration and steps were more pronounced when tested in the OFF-phase of the medication cycle. The significant interaction effect of medication*group especially on turn duration and steps in the study of McNeely et al. also confirmed the important role of medication on turning behavior implicating a 
higher improvement on turning in freezers in comparison to non-freezers while onmedication [43].

The influence of turning-arc or spatial confounds on these parameters is more difficult to interpret, as each study used a different turning-arc (except for studies on turning on-the-spot and the turning while walking studies of Spildooren et al. [28,32,33] and Bengevoord et al. [31]). When the turning arc was not standardized, freezers had a higher turn duration and number of steps in combination with an increased turning arc in comparison to non-freezers [21]. It was suggested that the selfchosen wide-arc strategy in freezers was used to compensate for postural instability $[48,49]$ and to diminish the left-right asymmetry during turning and as such decreasing the occurrence of freezing [50-52]. Furthermore, Peterson et al. put forward that the preferred larger turning arc is compensatory for the poor coordination in narrow turns, expressed as an increased PCI in narrow turns in freezers [42]. These results strengthen the hypothesis that FOG is a result of an abnormal gait pattern generation in freezers which causes an inability to walk with a constant gait rhythm and eventually reaches a threshold resulting in FOG [53].When the turning arc decreases as a result of standardization [28,32] or spatial constraints [37], the number of steps and turn duration increases even further.

This review also indicated that the cranio-caudal sequence during turn preparation is decreased in freezers in comparison to non-freezers $[33,43]$ and was absent in trials with freezing [33] implying an en-bloc turn strategy may be a clue to why people freeze. In addition, the increased turn duration of freezers was especially visible in the first turning quadrant [31], which suggests a decreased turn initiation in freezers. However, a larger delay of head rotation was demonstrated in the freezer 
group in the study of Spildooren et al. and in the non-freezers group in the study of McNeely et al.

This contrasting result may be attributed to the difference in definition of rotation onset time. Spildooren et al. described this onset time in relation to the distance of the turning marker (i.e. absolute delay), whereas McNeely calculated this metric as a percentage of the first stride during turning (i.e. relative delay). Head pelvis dissociation (i.e. turn preparation, maximum head-pelvis separation and timing of maximum headpelvis separation) was related to turn velocity and neck rigidity [33]. The influence of turning angle or turning-arc on axial rotation parameters has not been investigated so far.

The COM behavior during turning was comparable between freezers and non-freezers [31]. However, before a FOG episode, COM was characterized by an increased anterior and decreased medial position. This finding strengthens another hypothesis of Nutt et al. [53] suggesting that FOG is a result of an abnormal coupling between posture and gait characterized by multiple anticipatory postural adjustments and consequently an impaired COM deviation.

The present review revealed a relationship between stepping problems in freezers and increasing rotational demands during the turn (i.e. increasing turning angle or decreasing turning arc). This interesting finding may be ascribed to an increased axial rigidity, as the PIGD subtype is related to an increased axial rigidity in comparison to the tremor dominant subtype [54] and PIGD (postural instability gait difficulty) scores were often higher in freezers.

\section{Strengths and Limitations}


This review has several strengths. First, study selection was carried out by two independent raters. Second, a detailed methodological quality assessment was also carried out by two independent raters. However, the research strategy included only articles in English or Dutch available in two databases (i.e. Web of Science and Pubmed) and thus some information may have been missed. The majority of the included articles were limited by a small sample size and were not powered a priori. Some studies were performed during the off-state and others during the on-state of the medication cycle. In some studies groups were not matched for disease severity, hampering the comparison between studies. Especially, the PIGD score was systematically higher in freezers than in non-freezers [33,39,41]. Further, the in- or exclusion of freezing trials can explain the variability between the outcomes of different studies. Treatment-effects or dual-tasking were excluded in this review except for two studies which included a semi-dual task during the turn [27,38]. However, the in- or exclusion of these studies had no effect on the meta-analysis of turn duration.

\section{Clinical Implication}

Even though freezers prefer to adopt a wide turning-arc, avoiding tight turns are not realistic in daily life. Hence, recent study showed that turning in narrow spaces can be improved by 'clock-turning' [55]. During clock turning and not normal turning, the freezing frequency and duration decreased while turn parameters and foot clearance improved. Also turning can be improved in freezers by using a head attention strategy [56]. When turning was consciously initiated with head rotation, en-bloc turning in freezers was normalized. However, the influence of this attentional strategy on ameliorating freezing was not found to be significant. Furthermore, it was demonstrated that after only one rotating treadmill training, freezing frequency decreased significantly 
while turning in a pilot study [57]. This was confirmed in a study with a larger sample size, which showed that after 4 to 6 weeks of rotating treadmill training, freezing and turning improved [58]. These effects remained after one month follow-up and were ascribed to increases of the podokinetic after-rotation effects (i.e. turning in circles when asked to walk straight ahead without vision) [59]. This improved turn performance was not seen in a group of non-freezers after 1 or 5 days of training [60], suggesting a group specific effect for freezers.

\section{Future Research}

Until now, studies on turning in freezers focused especially on group differences between freezers and non-freezers. In most of the studies freezing-episodes were excluded. To understand the influence of turning on freezing, a different research approach should be suggested. Future studies should compare freezing-trials and normal turning trials within the same persons with freezing of gait. However, this implies larger sample sizes and more turning trials within the same person to assure both trials with and without freezing. The use of sensor-based technology may facilitate this type of data collection [39] as turning difficulties [61] and FOG [47] are difficult to provoke in a laboratory setting.

Even though studies on step parameters during turning were well represented, information on COM and rotational parameters were sparse in this review.

\section{Conclusions}

The turning performance of freezers differed consistently from non-freezers and was characterized by an increased turn duration, total steps and cadence and a decreased peak turn velocity. The fact that this pattern became stronger with an increasing turning 
angle was a constant finding across cohorts and may point to the involvement of the vestibular system in freezing of gait.

\section{Declaration of Interests}

The authors report no declarations of interest

\section{References}

[1] Giladi N, McDermott MP, Fahn S, et al. Freezing of gait in PD, Prospective assessment in the DATATOP cohort. Neurology 2001;56:1712-1721.

[2] Macht M, Kaussner Y, Möller JC, et al. Predictors of freezing in Parkinson's Disease: A survey of 6620 patients. Mov Disord. 2007;22(7):753-956.

[3] Bloem BR, Hausdorff JM, Visser JE, et al. Falls and freezing of gait in Parkinson's disease: a review of two interconnected, episodic phenomena. Mov Disord. 2004;19:871-884.

[4] Giladi N, Nieuwboer A. Understanding and treating freezing of gait in parkinsonism, proposed working definition, and setting the stage. Mov Disord. 2008;23(Supp12):S423-425. doi: 10.1002/mds.21927. Erratum in: Mov Disord. 2008;23(11):1639-1640.

[5] Michalowska M, Fiszer U, Krygowska-Wajs A, et al. Falls In Parkinson's disease. Causes and impact on patients' quality of life. Funct neurol. 2005;20(4):163-168.

[6] Rahman S, Griffin HJ, Quinn NP, et al. Quality of life in Parkinson's disease: the relative importance of the symptoms. Mov Disord. 2008;23(10):1428-1434.

[7] Tan DM, McGinley JL, Danoudis ME, et al. Freezing of gait and activity limitations in people with Parkinson's disease. Arch Phys Med rehabil. 2011;92:1159-1165. 
[8] Schaafsma JD, Balash Y, Gurevich T, et al. Characterization of freezing of gait subtypes and the response of each to levodopa in Parkinson's disease. Eur J Neurol. 2003;10:391-398.

[9] Hausdorff JM, Balash J, Giladi N. Effects of cognitive challenge on gait variability in patients with Parkinson's disease. J Geriatr Psychiatry Neurol. 2003;16(1),53-58.

[10] Heremans E, Nieuwboer A, Vercruysse S. Freezing of gait in Parkinson's disease: where are we now? Curr Neurol Neurosci Rep. 2013;13(6),350.

[11] Glaister BC, Bernatz GC, Klute GK, et al. Video task analysis of turning during activities of daily living. Gait posture. 2007;25:289-294.

[12] Strike SC, Taylor MJD. The temporal-spatial and ground reaction impulses of turning gait: Is turning symmetrical? Gait Posture. 2009;29:597-602.

[13] Courtine G, Schieppati M. Human walking along a curved path. I. Body trajectory, segment orientation and the effect of vision. Eur J Neurosc. 2003;18:177190.

[14] Courtine G, Schieppati M. Human walking along a curved path. II. Gait features and EMG patterns. Eur J Neurosc. 2003;18:191-205.

[15] Grasso R, Glasauer S, Takei Y, et al. The predictive brain: anticipatory control of head direction for the steering of locomotion. Neuro Report. 1996;7:1170-1174.

[16] Grasso R, Prèvost P, Ivanenko YP, et al. Eye-head coordination for the steering of locomotion in humans: an anticipatory synergy. Neuroscience Letters. $1998 ; 253: 115-118$.

[17] Orendurff MS, Segal AD, Berge JS, et al. The kinematics and kinetics of turning: limb asymmetries associated with walking a circular path. Gait Posture 2006;23:106-111. 
[18] Huxham F, Gong J, Baker R, et al. Defining spatial parameters for non-linear walking. Gait Posture. 2006;23:159-163.

[19] Salarian A, Zampieri C, Horak FB, et al. Analyzing $180^{\circ}$ turns using an inertial system reveals early signs of progression of Parkinson's disease. Conf Proc IEEE Eng Med Biol Soc. 2009;2009:224-227.

[20] Hulbert S, Ashburn A, Robert L, et al. A narrative review of turning deficits in people with Parkinson's disease. Disabil Rehab. 2015; 37(15):1382-1389.

[21] Crenna P, Carpinella I, Rabuffetti M, et al. The association between impaired turning and normal straight walking in Parkinson's disease. Gait posture. 2007;26:172-178.

[22] Willems AM, Nieuwboer A, Chavret F, et al. Turning in Parkinson's disease patients and controls: the effect of auditory cues. Mov Disord. 2007;22(13):18711878.

[23] Huxham F, Baker R, Morris ME, et al. Footstep adjustments used to turn during walking in Parkinson's disease. Mov Disord. 2008;23(6):817-823.

[24] Carpinella I, Crenna P, Calabrese E, et al. locomotor function in the early stage of Parkinson's disease. IEEE Trans Neural Syst Rehabil Eng. 2007;15(4):543-551.

[25] Stack EL, Ashburn AM, Jupp KE. Strategies used by people with Parkinson's disease who report difficulty turning. Parkinsonism Relat Disord. 2006;12:87-92.

[26] Snijders AH, Haaxma CA, Hagen YJ, et al. Freezer or non-freezer: Clinical assessment of freezing of gait. Parkinsonism Relat disord. 2012;18:149-154.

[27] Nieuwboer A, Baker K, Willems AM, et al. The short-term effects of different cueing modalities on turn speed in people with Parkinson's Disease. Neurorehab Neural Repair. 2009;23(8):831-836. Doi:10.1177/1545968309337136 
[28] Spildooren J, Vercruysse S, Desloovere K, et al. Freezing of gait in Parkinson's Disease: The impact of dual-tasking and turning. Mov Disord. 2010;25(15):25632570. DOI: $10.1002 / \mathrm{mds} .23327$

[29] Moher D, Shamseer L, Clarke M, et al. Preferred reporting items for systematic review and meta-analysis protocols (PRISMA-P) 2015 statement. Systematic reviews. 2015;4:1-9.

[30] Vandenbroucke JP, von Elm E, Douglas G, et al. Strengthening the reporting of observational studies in epidemiology (STROBE): Explanation and elaboration. Ann Intern Med. 2007;147(8):W163-W194.

[31] Bengevoord A, Vervoort G, Spildooren J, et al. Center of mass trajectories during turning in patients with Parkinson's disease with and without freezing of gait. Gait Posture. 2016;43:54-59. Doi:10.1016/j.gaitpost.2015.10.021

[32] Spildooren J, Vercruysse S, Meyns P, et al. Turning and unilateral cueing in Parkinson's disease patients with and without freezing of gait. Neuroscience. 2012;207:298-306. Doi:10.1016/j.neuroscience.2012.01.024

[33] Spildooren J, Vercruysse S, Heremans E, et al. Head-Pelvis coupling is increased during turning in patients with Parkinson's Disease and Freezing of Gait. Mov Disord 2013;28(5):619-625. Doi:10.1002/mds.25285

[34] Vervoort G, Heremans E, Bengevoord A, et al. Dual-task-related neural connectivity changes in patients with Parkinson's Disease. Neuroscience 2016;317:36-46. Doi:10.1016/j.neuroscience.2015.12.056

[35] Bhatt H, Pieruccini-Faria F, Almeida QJ. Dynamics of turning sharpness influences freezing of gait in Parkinson's Disease. Parkinsonism Relat Disord. 2013; 19:181-185. Doi:10.1016/j.parkreldis.2012.09.006 
[36] Sijobert B, Azevedo-Coste C, Andreu D, et al. Effects of sensitive electrical stimulation based cueing in Parkinson's disease: a preliminary study. Eur J Transl Myol. 2016;26(2):122-128.

[37] Fietzek UM, Stuhlinger L, Plate A, et al. Spatial constraints evoke increased number of steps during turning in Parkinson's disease. Clin Neurophysiol. 2017;128:1954-1960.

[38] Arias P, Cudeiro J. Effect of Rythmic auditory stimulation on gait in Parkinsonian patients with and without freezing of gait. PLos ONE 2010;5(3):e9675. Doi:10.1371/jounal.pone.0009675

[39] Mancini M, Smulders K, Cohen RG, et al. The clinical significance of freezing while turning in Parkinson's Disease. Neuroscience 2017;343:222-228.

[40] Lohnes CA, Earhart GM. Saccadic eye movements are related to turning performance in Parkinson's disease. J Parkinsons Dis. 2011;1(1):109-118. Doi:10.3233/JPD-2011-11019

[41] de Souza Fortaleza AC, Mancini M, Carlson-Kuhta P, et al. Dual task interference on postural sway, postural transitions and gait in people with Parkinson's disease and freezing of gait. Gait Posture. 2017;56:76-81.

[42] Peterson DS, Plotnik M, Hausdorff JM, et al. Evidence for a relationship between bilateral coordination during complex gait tasks and freezing of gait in Parkinson's disease. Parkinsonism Relat Disord. 2012;18(9):1022-1026. Doi:10.1016/j.parkreldis.2012.05.019

[43] McNeely ME, Earhart GM. The effects of medication on turning in people with Parkinson disease with and without freezing of gait. J Parkinsons Dis. 2011;1(3):259-270. Doi:10.3233/JPD-2011-11030 
[44] Giladi N, Tal J, Azulay T, et al. Validation of the freezing of gait questionnaire in patients with Parkinson's Disease. Mov Disord. 2009;24:655-661.

[45] Nieuwboer A, Rochester L, Herman T, et al. Reliability of the new freezing of gait questionnaire : agreement between patients with Parkinson's Disease and their carers. Gait Posture. 2009;30:459-463.

[46] Plotnik M, Giladi N, Hausdorff JM. A new measure for quantifying the bilateral coordination of human gait: effects of aging and Parkinson's disease. Experimental Brain Research. 2007;181(4):561-70.

[47] Nieuwboer A, Giladi N. The challenge of evaluating freezing of gait in patients with Parkinson's Disease. Br J Neurosurg. 2008;22(1):S16-18.

[48] Stack E, Jupp E, Ashburn A. Developing methods to evaluate how people with Parkinson's disease turn $180^{\circ}$ An activity frequently associated with falls. Disabil Rehabil. 2004;26:478-484.

[49] Thigpen MT, Light KE, Ceel GL, et al. Turning difficulty characteristics of adults aged 65 years or older. Phys Ther 2000;80:1174-1187.

[50] Kerr GK, Worringham CJ, Cole MH, et al. Predictors of future falls in Parkinson disease. Neurology 2010;75(2):116-124. doi:10.1212/WNL.0b013e3181e7b688.

[51] Paul SS, Canning CG, Sherrington C, et al. Three simple clinical tests to accurately predict falls in people with Parkinson's disease. Mov Disord. 2013;28(5):655-562. doi: 10.1002/mds.25404.

[52] Plotnik M, Giladi N, Balash Y, et al. Is freezing of gait in Parkinson's disease related to asymmetric motor function? Ann Neurol. 2005;57(5):656-663.

[53] Nutt JG, Bloem BR, Giladi N, et al. Freezing of gait: moving forward on a mysterious clinical phenomenon. Lancet Neurol. 2011; 10(8):734-744. 
[54] Li-Jun Z, Ying-Shan P, Li-Xia L, et al. Phenotype of postural instability/gait difficulty in Parkinson disease: relevance to cognitive impairment and mechanism relating pathological proteins and neurotransmitters. Sci Rep. 2017; 7: 44872.

[55] Yang W-C, Hsu W-L, Wu R-M, et al. Immediate effects of clock-turn strategy on the pattern and performance of narrow turning in persons with Parkinson Disease. J Neurol Phys Ther. 2016;40:249-256.

[56] Spildooren J, Vercruysse S, Heremans E, et al. Influence of Cueing and an Attentional Strategy on Freezing of Gait in Parkinson Disease During Turning. J Neurol Phys Ther. 2017;41(2):129-135.

[57] Hong M, Earhart GM. Rotating treadmill training reduces freezing in Parkinson disease: preliminary observations. Parkinsonism Relat Disord. 2008;14(4):359-363.

[58] Cheng F-Y, Yang Y-R, Wu Y-R, et al. Effects of curved-walking training on curved-walking performance and freezing of gait in individuals with Parkinson's disease: A randomized controlled trial. Parkinsonism Relat Disord. 2017; 43:20-26.

[59] Godi M, Giardini M, Nardone A, et al. Curved walking rehabilitation with a rotating treadmill in patients with Parkinson's Disease: A proof of concept. Front Neurol. 2017;8:53.

[60] McNeely ME, Earhart GM. Lack of short-term effectiveness of rotating treadmill training on turning in people with mild-to-moderate Parkinson's Disease and Healthy older adults: A randomized, controlled study. Hindawi Publishing Corporation Parkinson's Disease 2012;2012:623985

[61] Mancini M, El-Gohary M, Pearson S, et al. Continuous monitoring of turning in Parkinson's disease: Rehabilitation potential. NeuroRehabilitation. 2015;37(1):3-10. 


\section{Figure Captions}

Figure 1. Flowchart of study selection according to PRISMA (Preferred Reporting Items for Systematic Reviews and Meta-Analyses).

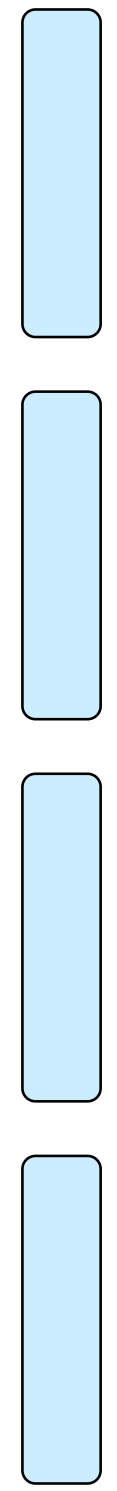

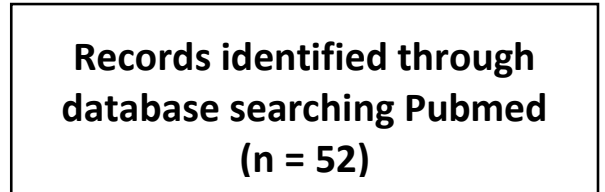

$(n=52)$

\section{Records identified through}

database searching Web of
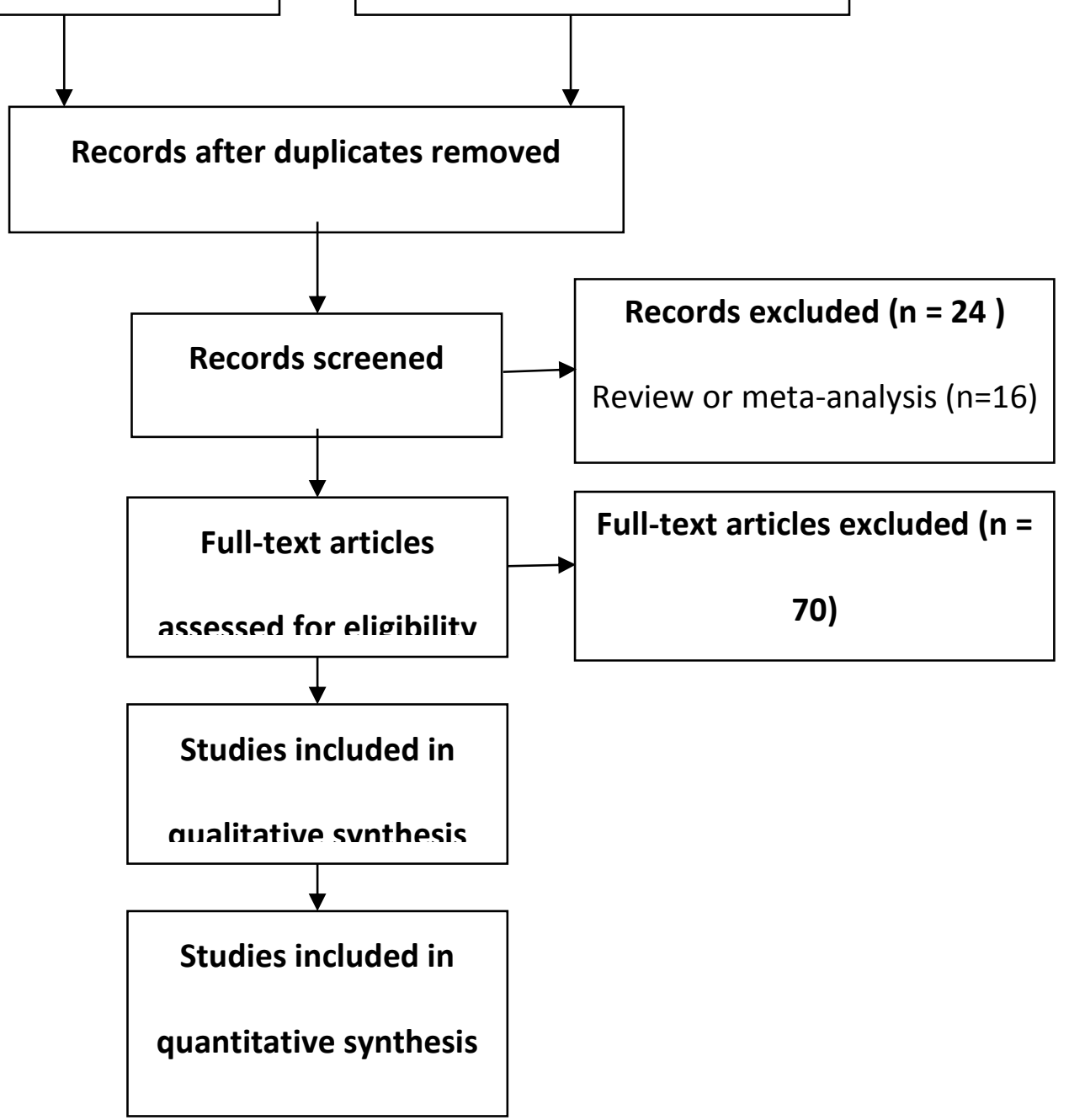
Figure 2. Turn duration in freezers versus non-freezers during $90^{\circ}, 180^{\circ}$ and $360^{\circ}$ turning.

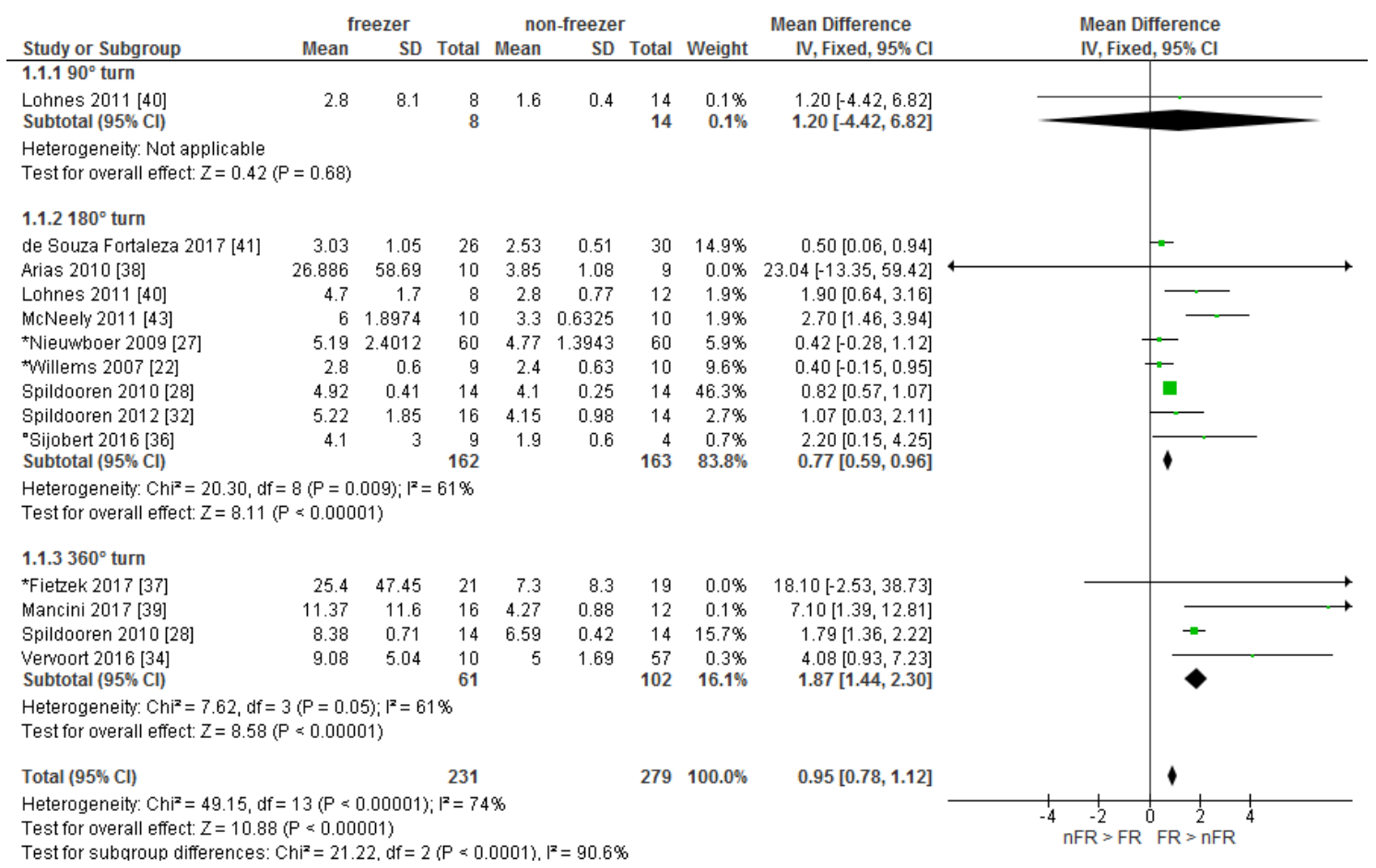

FR, freezers; nFR, non-freezers

$*=$ testing during the on-phase of the medication cycle

${ }^{\circ}=$ No information about medication intake

Figure 3. Peak turn velocity in freezers versus non-freezers.

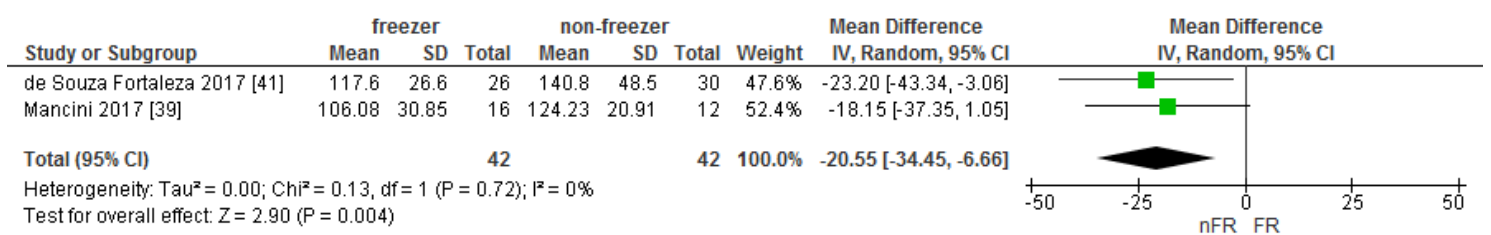

FR, freezers; nFR, non-freezers 
Figure 4. Turn steps in freezers versus non-freezers during $90^{\circ}, 180^{\circ}$ and $360^{\circ}$ turning. FR, freezers; nFR, non-freezers

\begin{tabular}{|c|c|c|c|c|c|c|c|c|c|c|c|c|}
\hline \multirow[b]{2}{*}{ Study or Subgroup } & \multicolumn{3}{|c|}{ freezer } & \multicolumn{3}{|c|}{ non-freezer } & \multicolumn{3}{|c|}{ Mean Difference } & \multirow{2}{*}{\multicolumn{2}{|c|}{$\begin{array}{l}\text { Mean Difference } \\
\text { IV, Random, } 95 \% \mathrm{Cl}\end{array}$}} & \\
\hline & Mean & SD & Total & Mean & SD & Total & Weight & IV, Random, $95 \% \mathrm{Cl}$ & & & & \\
\hline \multicolumn{13}{|l|}{ 1.2.190 turn } \\
\hline $\begin{array}{l}\text { Lohnes } 2011[40] \\
\text { Subtotal }(95 \% \mathrm{Cl})\end{array}$ & 6.4 & 3.6 & $\begin{array}{l}8 \\
8\end{array}$ & 3.1 & 0.5 & $\begin{array}{l}14 \\
14\end{array}$ & $\begin{array}{l}11.8 \% \\
11.8 \%\end{array}$ & $\begin{array}{l}3.30[0.79,5.81] \\
3.30[0.79,5.81]\end{array}$ & & & & \\
\hline \multicolumn{13}{|c|}{ Heterogeneity: Not applicable } \\
\hline \multicolumn{13}{|l|}{$1.2 .2180^{\circ}$ turn } \\
\hline *Willems 2007 [22] & 5.9 & 1.26 & 10 & 5.2 & 0.95 & 10 & $16.3 \%$ & $0.70[-0.28,1.68]$ & & & - & \\
\hline Lohnes 2011 [40] & 11.1 & 6.7 & 8 & 5.4 & 1.1 & 12 & $6.6 \%$ & $5.70[1.02,10.38]$ & & & & \\
\hline McNeely 2011 [43] & 13.7 & 4.4272 & 10 & 6.5 & 1.8974 & 10 & $10.4 \%$ & $7.20[4.21,10.19]$ & & & & \\
\hline Spildooren 2010 [28] & 9.76 & 1.07 & 14 & 7.14 & 0.44 & 14 & $17.0 \%$ & $2.62[2.01,3.23]$ & & & - & \\
\hline $\begin{array}{l}\text { Spildooren } 2012[32] \\
\text { Subtotal }(95 \% \mathrm{Cl})\end{array}$ & 10.32 & 5.1 & $\begin{array}{l}16 \\
58\end{array}$ & 7.32 & 1.64 & $\begin{array}{l}14 \\
60\end{array}$ & $\begin{array}{l}11.4 \% \\
61.7 \%\end{array}$ & $\begin{array}{l}3.00[0.36,5.64] \\
3.19[1.44,4.94]\end{array}$ & & & & \\
\hline \multicolumn{13}{|c|}{$\begin{array}{l}\text { Heterogeneity: } \text { Tau }^{2}=2.64 ; \mathrm{Chi}^{2}=23.99, \mathrm{df}=4(\mathrm{P}<0.0001) ; \mathrm{I}^{2}=83 \% \\
\text { Test for overall effect: } Z=3.57(\mathrm{P}=0.0004)\end{array}$} \\
\hline \multicolumn{13}{|l|}{$1.2 .3360^{\circ}$ turn } \\
\hline $\begin{array}{l}\text { "Fletek } 201][37] \\
\text { Spildooren } 2010 \text { [28] }\end{array}$ & $\begin{array}{r}54.5 \\
16.89\end{array}$ & $\begin{array}{r}102.15 \\
1.7\end{array}$ & $\begin{array}{l}21 \\
14\end{array}$ & $\begin{array}{r}16 \\
11.62\end{array}$ & $\begin{array}{r}18.67 \\
0.72\end{array}$ & $\begin{array}{l}19 \\
14\end{array}$ & $\begin{array}{r}0.1 \% \\
16.3 \%\end{array}$ & $\begin{array}{r}38.50[-5.99,82.99] \\
5.27[4.30,6.24]\end{array}$ & & & -- & \\
\hline $\begin{array}{l}\text { Vervoort } 2016[34] \\
\text { Subtotal }(95 \% \mathrm{Cl})\end{array}$ & 14.45 & 4.65 & $\begin{array}{r}9 \\
44\end{array}$ & 10.51 & 2.77 & $\begin{array}{l}57 \\
90\end{array}$ & $\begin{array}{r}10.1 \% \\
26.5 \%\end{array}$ & $\begin{array}{l}3.94[0.82,7.06] \\
4.98[3.04,6.91]\end{array}$ & & & & \\
\hline \multicolumn{13}{|c|}{$\begin{array}{l}\text { Heterogeneity: } \text { Tau }^{2}=1.10 ; \mathrm{Chi}^{2}=2.79, \mathrm{df}=2(P=0.25) ;\left.\right|^{2}=28 \% \\
\text { Test for overall effect: } Z=5.03(P<0.00001)\end{array}$} \\
\hline Total $(95 \% \mathrm{Cl})$ & & & 110 & & & 164 & $100.0 \%$ & $3.72[2.20,5.24]$ & & & & \\
\hline $\begin{array}{l}\text { Heterogeneity: } \operatorname{Tau}^{2}= \\
\text { Test for overall effect: } \\
\text { Test for subqroup diffe }\end{array}$ & $\begin{array}{l}.44 ; \mathrm{Chi}^{2} \\
=4.80( \\
\text { rences: }\end{array}$ & $\begin{array}{l}{ }^{2}=55.60 \\
P<0.000 \\
C h i^{2}=2.0\end{array}$ & $\begin{array}{l}d f=8 \\
01) \\
3 . d f=\end{array}$ & $\begin{array}{l}(P<0.0 \\
2(P=0\end{array}$ & $\begin{array}{l}0001) ;\left.\right|^{2}= \\
0.36)\left.\cdot\right|^{2}=\end{array}$ & $\begin{array}{l}=86 \% \\
1.5 \%\end{array}$ & & & -10 & $\begin{array}{ll}-5 \\
\mathrm{nFR}\end{array} \mathrm{FR}^{0}$ & 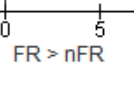 & 10 \\
\hline
\end{tabular}


Figure 5. Cadence in freezers versus non-freezers during $90^{\circ}, 120^{\circ}, 180^{\circ}$ and $360^{\circ}$ turning.

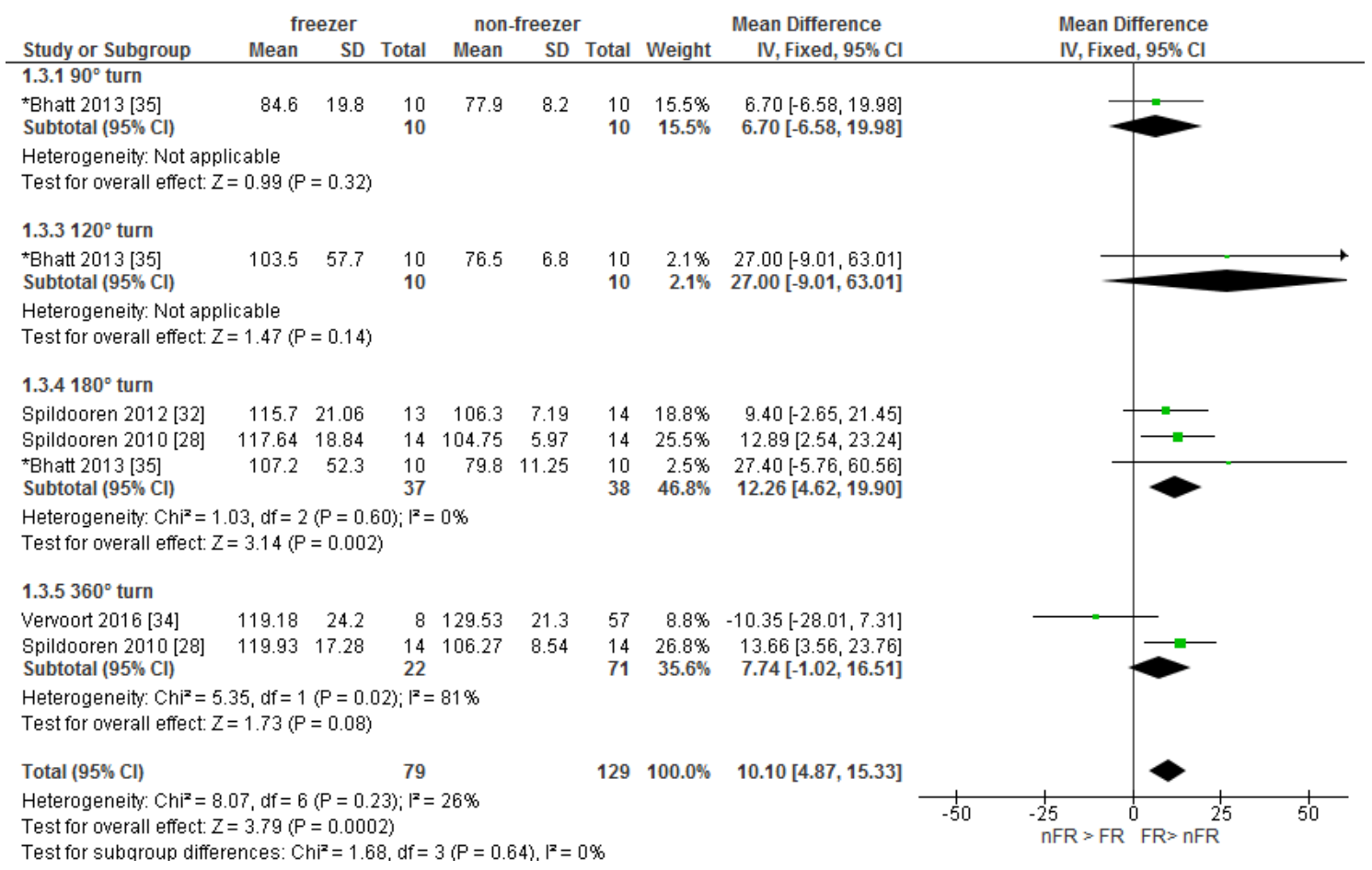

FR, freezers; nFR, non-freezers

$*=$ testing during the on-phase of the medication cycle

Figure 6. Step width in freezers versus non-freezers during $180^{\circ}$ turning.

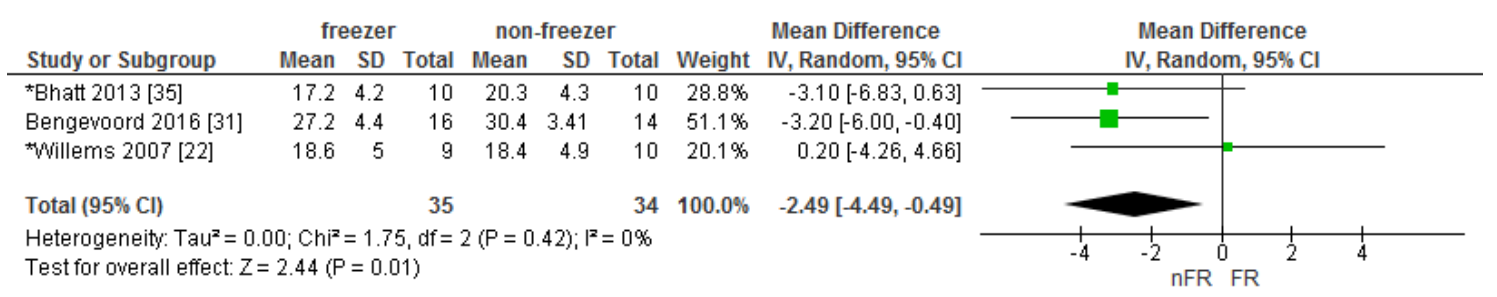

FR, freezers; nFR, non-freezers

$*=$ testing during the on-phase of the medication cycle 
Tables

Table 1: Characteristics of the included studies.

\begin{tabular}{|c|c|c|c|c|c|c|}
\hline Studies included & $\begin{array}{l}\text { FOG classification } \\
\text { method }\end{array}$ & Disease differences & ON/OFF & $\begin{array}{l}\text { Turning } \\
\text { angle }\end{array}$ & Turn characteristics & $\begin{array}{l}\text { FOG-trials } \\
\text { included? }\end{array}$ \\
\hline $\begin{array}{l}\text { Arias P, et al., } \\
2010[38]\end{array}$ & $\begin{array}{l}\text { Medical records } \\
\text { FOG-Q item } 3\end{array}$ & UPDRS-III = & OFF & $180^{\circ}$ & $\begin{array}{l}\text { While walking, } \\
\text { unstandardized, DT }\end{array}$ & YES \\
\hline $\begin{array}{l}\text { Bengevoord A., et } \\
\text { al., } 2016 \text { [31] }\end{array}$ & NFOGQ & $\begin{array}{l}\text { DD }= \\
\text { UPDRS-III = } \\
H \& Y=\end{array}$ & OFF & $180^{\circ}$ & $\begin{array}{l}\text { While walking, } \\
\text { radius standardised }\end{array}$ & NO/YES \\
\hline $\begin{array}{l}\text { Bhatt H, et al., } \\
2013 \text { [35] }\end{array}$ & Observation & UPDRS-III = & ON & $\begin{array}{l}90^{\circ} \\
120^{\circ} \\
180^{\circ}\end{array}$ & $\begin{array}{l}\text { While walking, } \\
\text { radius standardised }\end{array}$ & YES \\
\hline $\begin{array}{l}\text { De Souza } \\
\text { Fortaleza AC, et al. } \\
2017 \text { [41] }\end{array}$ & NFOGQ & $\begin{array}{l}\mathrm{DD}= \\
\text { MDS-UPDRS-III = } \\
\mathrm{PIGD}>\end{array}$ & OFF & $180^{\circ}$ & $\begin{array}{l}\text { While walking, } \\
\text { unstandardized, }\end{array}$ & - \\
\hline $\begin{array}{l}\text { Fietzek UM, et al., } \\
2017 \text { [37] }\end{array}$ & FOG-Q item 3 & $\begin{array}{l}\text { DD > } \\
\text { MDS-UPDRS-III > } \\
H \& Y=\end{array}$ & ON & $360^{\circ}$ & $\begin{array}{l}\text { On the spot, radius } \\
\text { standardised }\end{array}$ & YES \\
\hline $\begin{array}{l}\text { Lohnes CA, et al., } \\
2011[40]\end{array}$ & FOG-Q item 3 & $\begin{array}{l}\text { DD }= \\
\text { MDS-UPDRS-III = }\end{array}$ & OFF & $\begin{array}{l}90^{\circ} \\
180^{\circ}\end{array}$ & On the spot & - \\
\hline $\begin{array}{l}\text { Mancini M, et al., } \\
2017 \text { [39] }\end{array}$ & $\geq 3$ on NFOGQ & $\begin{array}{l}\text { UPDRS-III }>^{a} \\
\text { PIGD }^{a}\end{array}$ & OFF & $360^{\circ}$ & On the spot & YES \\
\hline $\begin{array}{l}\text { McNeely ME, et } \\
\text { al., } 2011 \text { [43] }\end{array}$ & FOG-Q item 3 & $\begin{array}{l}\mathrm{DD}= \\
\text { UPDRS-III = }\end{array}$ & ON/OFF & $180^{\circ}$ & On the spot & NO \\
\hline $\begin{array}{l}\text { Nieuwboer A, et } \\
\text { al., } 2009 \text { [27] }\end{array}$ & FOG-Q item 3 & $\begin{array}{l}\mathrm{DD}= \\
\text { UPDRS-III = } \\
\mathrm{H} \& \mathrm{Y}=\end{array}$ & ON & $180^{\circ}$ & $\begin{array}{l}\text { While walking, } \\
\text { unstandardized, DT }\end{array}$ & NO \\
\hline $\begin{array}{l}\text { Peterson DS, et al., } \\
2012 \text { [42] }\end{array}$ & FOG-Q item 3 & $\begin{array}{l}\mathrm{DD}= \\
\text { MDS-UPDRS-III = }\end{array}$ & OFF & $>360^{\circ}$ & radius standardised & YES \\
\hline $\begin{array}{l}\text { Sijobert B, et al., } \\
2016 \text { [36] }\end{array}$ & Observation & - & - & $180^{\circ}$ & $\begin{array}{l}\text { While walking, } \\
\text { unstandardized, }\end{array}$ & - \\
\hline $\begin{array}{l}\text { Spildooren J, et al., } \\
2010 \text { [28] }\end{array}$ & NFOGQ & $\begin{array}{l}\mathrm{DD}= \\
\text { UPDRS-III = } \\
\mathrm{H} \& \mathrm{Y}=\end{array}$ & OFF & $\begin{array}{l}180^{\circ} \\
360^{\circ}\end{array}$ & $\begin{array}{l}\text { While walking, } \\
\text { radius standardised }\end{array}$ & NO \\
\hline $\begin{array}{l}\text { Spildooren J, et al., } \\
2012 \text { [32] }\end{array}$ & NFOGQ & $\begin{array}{l}\mathrm{DD}= \\
\text { UPDRS-III = } \\
\mathrm{H} \& \mathrm{Y}=\end{array}$ & OFF & $180^{\circ}$ & $\begin{array}{l}\text { While walking, } \\
\text { radius standardised }\end{array}$ & NO \\
\hline $\begin{array}{l}\text { Spildooren J, et al., } \\
2013 \text { [33] }\end{array}$ & NFOGQ & $\begin{array}{l}\text { DD }= \\
\text { UPDRS-III = } \\
H \& Y=\end{array}$ & OFF & $180^{\circ}$ & $\begin{array}{l}\text { While walking, } \\
\text { radius standardised }\end{array}$ & NO \\
\hline $\begin{array}{l}\text { Vervoort G, et al., } \\
2016 \text { [34] }\end{array}$ & NFOGQ & $\begin{array}{l}\mathrm{DD}= \\
\text { MDS-UPDRS-III > } \\
\mathrm{H} \& Y=\end{array}$ & OFF & $360^{\circ}$ & $\begin{array}{l}\text { While walking, } \\
\text { radius standardised }\end{array}$ & NO \\
\hline $\begin{array}{l}\text { Willems AM, et al., } \\
2007 \text { [22] }\end{array}$ & FOG-Q item 3 & $\begin{array}{l}\text { DD }> \\
\text { UPDRS-III = } \\
H \& Y=\end{array}$ & ON & $180^{\circ}$ & $\begin{array}{l}\text { While walking, } \\
\text { unstandardized }\end{array}$ & NO \\
\hline
\end{tabular}

Not reported (-); no significant differences between FR and $\mathrm{nFR}(=)$; significantly higher in FR compared to $\mathrm{nFR}(>)$; significantly lower in FR compared to nFR (<). FOG, freezing of gait; FOG-Q, Freezing of Gait Questionnaire; DD, disease duration; H \& Y, Hoehn and Yahr stage; NFOG-Q, New Freezing of Gait Questionnaire; UPDRS-III, Unified Parkinson's Disease Rating Scale part III (motor examination); MDS-UPDRS-III, new modified version of UPDRS. a Analysis was statistically accounted for confounders. 